\title{
Application of Information System in the Education Industry of Pakistan
}

\author{
Muhammad Kamran Jamil \& Syed Asad Hussain \\ SZABIST \\ Karachi, Pakistan
}

\begin{abstract}
:
Technology is now a key factor in driving the economies of the world. Whether it is the field of pure or medical sciences; management or social science; technology's involvement and influence is there. Technology and its fast adoption have not only changed the traditional way of doing businesses but also directly affected the individual personalities, societies and nations. It has increased the efficiency, horizon the span of knowledge and strengthened the medium of information seeking. Technology has its own merits and demerits but it depends on how it is used, when and where it is applicable and what technology may be used in specific situation or circumstances. Firstly, effective use of technology has brought in drastic changes in organizations comparing with the traditional way of doing business that lead to business processes redesigning and reengineering. Secondly due to globalization, transfer and adoption of technology is faster than it was before. Now the technology-based nations are successful and way ahead and have direct influence on the nations who are lacking behind in the adoption of technology.
\end{abstract}

Now IT is widely used to develop information systems. Information System has played a major role in almost all the industries of Pakistan. Similar to other industries, educational institutions have also incorporated IT to develop their information systems to bring operational efficiency in academic administrative matters. The core function of any institution is to provide education to students. As Information Technology has changed the way of doing business, similarly, it has changed the traditional way of seeking knowledge. Unlimited educational information is available through Internet, which does not only facilitate students and researchers to get online information but also help them to share information and views across the borders. With the innovation of Internet technology and its wide usage, there is no physical barrier to information and knowledge. Due to removal of this barrier organizations' emphasis towards hiring and employing "knowledge workers" has been increased. The secondary function, which supports the core function of any institute, is the academic administration. In addition to the curriculum, students are encountered with academic administrative matters before getting enrollment and even after it till completion of studies. Students need admission information, course curriculum details and filing enrolment procedures before getting registered in any institution's program. Information which has direct involvement of students while studying such as availability of notes and reference materials, result, class schedule, accounts status, university's programs, etc. There are other information which is not directly required by the students but institutions have to maintain it in order to provide efficient service to students such as data related to student admission formalities and submission of documents, registration into next semesters, result information, students' fee payment status, faculty compensation or reimbursement, staff/HR information system, library information system, etc. If the institutions do not have such information systems applicable, they might do the same manually which has obviously resulted in delaying academic and administrative decisions.

\section{INTRODUCTION}

Explosion of Information Technology (IT) has led to the development Information Systems Management and hence changed the traditional management practices. Information Systems and Database Management Systems facilitate speedily processing, fast accesses to data, vast storage, reliable and consistent retrieval and hence improved decision making, planning and implementation process.

To remain competitive in the global environment, one has to be conformant with the latest IS Management practices. Fast access to information and capitalizing the opportunity through quick decision-making are the keys to success. Business Process Re-engineering (BPR), Enterprise Resource Planning (ERP), MRP - II (Manufacturing Resource Planning), Customer Relationship Management (CRM) and Supply-Chain Management (SCM) are some of the major Information Systems which have fastened the pace of business operations and eliminate the physical boundaries. Today's organizations are turning their operations towards computerization to achieve effectiveness and efficiency in order to cater larger market share. Use of Information Systems is becoming common in large local and multinational organizations in Pakistan but most of the medium and small enterprises are still ignorant with the use and application of Information Systems. [1]

Information systems are designed in any organization for the following reasons:

- The internal and external customers of the organizational processes

- The products/services generated by the organization's processes

- The steps involved in performing list of activities

- The participants in the organizational processes

- The information that organization's process uses or creates

- The technology that organization's process uses 
In any organization, operations framework consisting of following elements:

- Business processes - activities performed in an organizational environment

- Participants - involved in business processes

- Information - knowledge participants share while performing the tasks

- Information Technology - tools used to share information

The information system is therefore the part of the system that happens to use information and information technology. Adopting this viewpoint helps in resisting the tendency to analyze information system as purely technical systems without regard to why they exist. The tendency is probably one of several key reasons for the ineffectiveness of many information technology applications. [2]

Information system in education industry is as important as database management of customers and sales in other industry. IS in Education industry facilitates following:

- in developing procedures for admission process/intake

- in maintaining students' record and their registration/enrollment status

- in locating/accessing relevant books through Library Information Systems

- in keeping students' accounts ledger up to date

- in establishing educational information (transfer/exchange) network through www

- in ensuring vigilant examination process

- in bringing out quick and reliable transcripts/statement of marks

- in communicating students globally

- in accessing institutions' information to remote areas

Further, there are systems similar to that of other industry like,

- computerized system for educational staff working in that institution

- maintaining payroll and accounting/financial modules/system

- inventory or stocking system

- procurement and purchasing

- general security system

- office automation

It is commonly perceived that IS in the education industry is not as important as in the other industries. As a matter of fact implementation of Information Systems in education industry has not only improved practices of educational administration but also has direct impact on the quality intake of students. The availability of institution's educational information, sharing of information, access to well-stocked libraries of the world, over the web has made knowledge 24-hour learning resource center. It facilitates students to select the courses, register in the new semesters and access to their results remotely. No matter whatever the complexities or difficulties, in order to operate smooth functioning of educational administration, implementation of IS in the education sector is must.[3]

\section{EDUCATION INDUSTRY IN PAKISTAN}

Education sector of any country has direct impact on the progress and prosperity of the nation. It is among the core necessities and a condition for economic development. The Pakistan had not made any significant progress in the education sector in the past, and hence the literacy rate in Pakistan very low. Due to this low literacy we are far away from new technologies adopted by developed nations in order to simplify the work and bring efficiency. Pakistan is located at a strategic place where it may become hub for Middle East, Far East, Central Asia and European countries. We need reform in education sector from primary to higher level in order to survive in global competitive environment. It is now time to stand up for Change! There are hundred of questions raised in our minds about higher education and its prospects in Pakistan; Why public universities are not imparting quality education? What is the role of Higher Education Commission or is there any difference by changing name from UGC to HEC? Are any strategic reform policies for Education or it is only limited to the papers? Is there any control mechanism or accountability on the private universities? What is the criteria for setting up an institution and are those criteria are followed? Is there any liaison between the institutions and industry? and number of other questions which puts a big question to our educational system and to the officials made responsible for the promotion of education in our country.

A quick comparison would tell us that private universities are teaching courses for which there is a market demand. Their salary structure is flexible and helps attract top professionals in any given subject. The public universities on the other hand have some department that do not seem to have any understanding of changed needs of the job market. And if that was not bad enough, some of he public university teachers continue to provide obsolete information to students. Consequently, an increasing number of students continue to get higher education that is of little or no relevance.[4]

Education Industry in Pakistan has brought revolution due to the entry of private sector. New and market-oriented programs have been introduced by private universities, which forced public universities to change their attitude if they want to survive. They have not only come up with the innovative programs but also brought in proper educational system. Traditionally, students were often put into academic administrative problems due to nonavailability of Educational Information System. Students' data, attendance record, marks sheet and online information were not available. Students were required to spend much of their time in order to streamline their 
academic administrative matters. With the introduction and fast adoption of Information Technology it has now become possible to have such information available but still there are public universities who have not taken initiative towards computerization of their academic operations.[5]

\section{APPLICATION OF INFORMATION SYSTEM IN THE EDUCATION INDUSTRY}

It has been known that many education systems around the world face accumulating economic and other pressures, and are unable to meet the needs of increasingly knowledge-intensive economies. With the emergence of the Internet, database, there is potential to completely alter the landscape for commerce, education and social-cultural interaction. Whereas IT merely enhanced productivity or the control over information, the Internet is a fundamentally different technology that reshapes our social and economic relationships. The uncontrolled growth of information is flooding universities and learners alike with knowledge from all kinds of resources.

At the same time, increasing competitiveness and globalization is creating needs for learning that extend far beyond theoretical scope, such as the need for lifelong and open learning. The change in the conception of knowledge and needs for learning has been characterized as shifts in learning towards an more-oriented, distributed, masscustomized and multi-node learning, complex and adaptive paradigm.

Given these changes, universities have to fundamentally rethink their roles. Universities and their elements need to be re-conceptualized within a broader setting that shows how they can be shaped to the needs of knowledge-based societies. The notions that need to be revised foremost are the ideas that they are static, slowly changing entities, that they are less responsive to societal needs than to their own, and that students are essentially containers to which contents must be "delivered".[6]

Application of information systems in the education industry has become essential in order to coordinate and share information to facilitate students in their routine academic administrative issues. By deploying information systems in the academic operations will not only increase the overall efficiency but also allows institutions to focus on academics which is their core function.[7]

Educational Information System (EIS) is same as any other system which facilitates management in decision making, planning, organizing, controlling and staffing. EIS stands for Educational Information Systems where students' data related to admissions, registration, examination, queries and institution's information are processed electronically with the help of computers. If we see towards public institutions, we found that there is hardly any institute, which has implemented EIS for their productivity. As far private institutions are concerned, they have enough orientation towards Information Systems and its benefits and therefore they have not only implemented but are trying their best to bring theses systems at par to international educational information systems. Most of the institutions in the private sector institutions have both comprehensive database system and a website for online interaction. The situation in the public sector institutions is entirely different and they are struggling hard to even have the website through which atleast they interact with the outside world.

It is perceived that information systems implementation needs huge investment but it is not true. It is only the matter of inclination and attitude towards implementing information system. It may be started from one PC and gradually be expanded over the network and then online. In the context of public institutions in particular and public institutions in general, currently, there are good number of institutions, which have implemented EIS on alone PC. They have their website and e-mail to respond queries electronically. Such institutions do not have full-fledged information systems either due to less priority and importance towards computerization or may not have infrastructure support i.e., lack of trained human resource, non-ability to compensate computer professionals or financial constraints. Further, there are institutions, which have application software or database management system, but they are not using it efficiently. They think that development of database system is sufficient for implementation of computerization or do not hire concerned computer professional to keep the information system operative. As far computerization in educational institutions is concerned, most of the institutions firstly prefer to have setup of computer labs for students and then to have computerization of students' data. If they don't have computer labs for students, which are now the primary requirement for all educational institutions, they will never think of computerization. With the increasing tendency towards computerization, it is encouraging to note that institution's management and government are trying to implement computerization at all levels. These efforts will not only help those institutions, which are planning for implementation of computerization in their academic operations but will force other institutions which are doing their operations manually to computerize their activities.[8]

Information Systems in educational institutions can be classified into two systems i.e., core and supplement ISs, which are as follows:

\section{Core Educational Information Systems}

1. Students' Info. Systems (admission \& registration)

2. Result/Transcript Information Systems

3. Testing/Evaluation System

4. Library Information Systems

5. Web Information Systems (web site)

6. Graduate/Alumni Information Systems 
Above systems are linked together to establish a comprehensive EIS and hence serve the purpose of handling all educational administrative issues.

\section{Supplement Educational Information Systems}

1. Human Resource Information System - HRIS (Faculty/Staff Information Systems)

2. Finance \& Accounting Information System - FIS (Payroll, cash flows, etc)

3. General Security Information System - GSIS

4. Office Automation (OA)

\section{FINDINGS}

From the survey we found that $88 \%$ of the institutions at post graduation level has either Computer or Database Department.

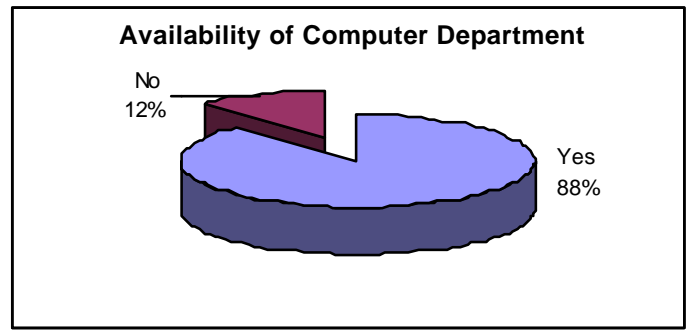

Majority of the institutions has somehow EIS applicable and out of sample size of 24 institutions, $79 \%$ of the institutions have EIS either at minor or major level and only $21 \%$ institutions do not have EIS at all. There are $40 \%$ institutions have computerization level upto 51 to $74 \%$ whereas $25 \%$ of the institutions are having computerization upto $21-50 \%$ and same percentage is of the institutions having $75-100 \%$ computerization in their institutions.

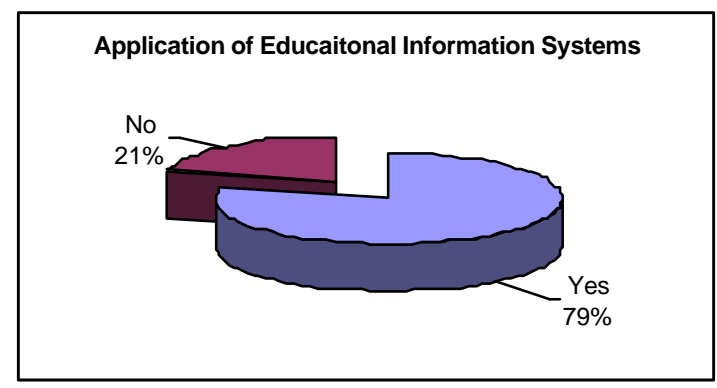

As far as separate computer and database department is concerned, most of the institutions i.e., 70\% institutions have one department for both computing and database operations whereas only $30 \%$ institutions have separate database department. $68 \%$ of the institutions' database is connected on the network whereas $32 \%$ institutions are operating their database on stand-alone system. Most of the institutions have less than 4 persons in their database department and it tends to $50 \%$ out of 20 institutions having computer or database department whereas $45 \%$ of the institutions have 4 to 8 staff in their database department. In most of the institutions, System Administrator looks after database.

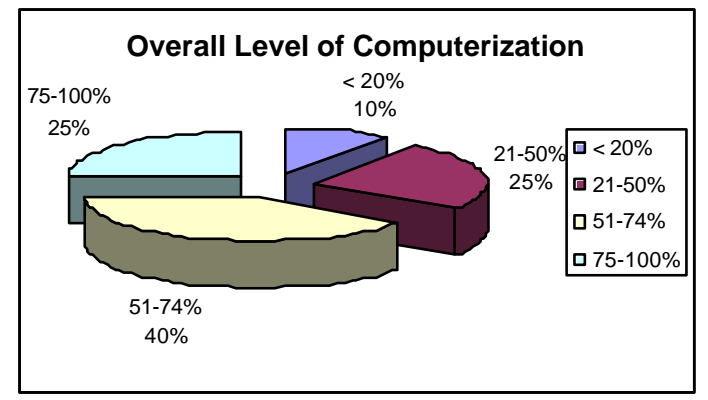

In most of the institutions, i.e., 33\%, EIS responsible person is reporting to Directors' level whereas in $25 \%$ of the case, EIS heads are reporting directly to Registrar or Vice Chancellor. It has come from the study that $40 \%$ of the institutions do not send their database staff for Training \& Development whereas only $10 \%$ of the institutions strongly believe on training \& development of EIS related staff. In most of the cases, the top management is either least concerned or somehow concerned for computerization in the institutions whereas $30 \%$ of the institutions' top management is very much concerned about computerization.

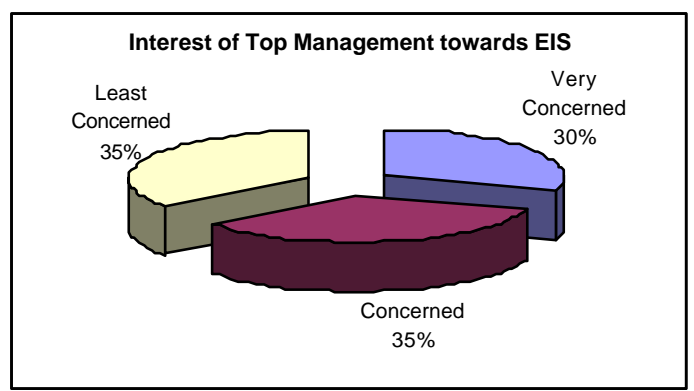

There are $15 \%$ of the institutions, which have fully implemented all core EIS in their institutions. The institutions even do not have all core EIS, but they are somehow working on Library Information System, Registration and Web Information Systems. Following is the statistics related to implementation of core EIS:

- Admission/Registration IS

$84 \%$

- Result IS

$89 \%$

- Examination IS

$42 \%$

- Library IS

$53 \%$

- Web Info. System

$84 \%$

- Graduate/Alumni IS

$37 \%$

In the supplement EIS, most of the institutions i.e., 100\% have implemented Financial Information System and Office Automation system. There are 19\% institutions are fully computerized in terms of supplement EIS which includes HRIS, FIS, GSS and OA. Brief statistics of implementation of supplement EIS is as follows: 
- Human Resource Information System (HRIS)

$37 \%$

- Financial Information System (FIS)

$100 \%$

- General Security System (GSS)

$32 \%$

- Office Automation

So far there is no institution is offering online admission facility to students but the work for this facility is under progress in few of the institutions. As far as computer literacy of faculty members is concerned, in $90 \%$ of the institutions faculty members are computer literate and their computer literacy level varies from 51 to $100 \%$. In most of the IT institutions, the computer literacy of faculty members is upto $100 \%$. In almost $80 \%$ of the institutions, faculty members are provided with Internet and e-mail facilities. It is appreciating to know that in $95 \%$ of the institutions' supporting staff is computer literate and it is because of the reason that most of the word processing tasks is now performed with the help of computers. In most of the institutions, the staff's computer literacy varies from 21 to $75 \%$ i.e., in $45 \%$ of the institutions whereas in other institutions staff's literacy rate is even within 51 $74 \%$. In almost $50 \%$ of the institutions staff are also provided with Internet and e-mail facility along with the faculty members.

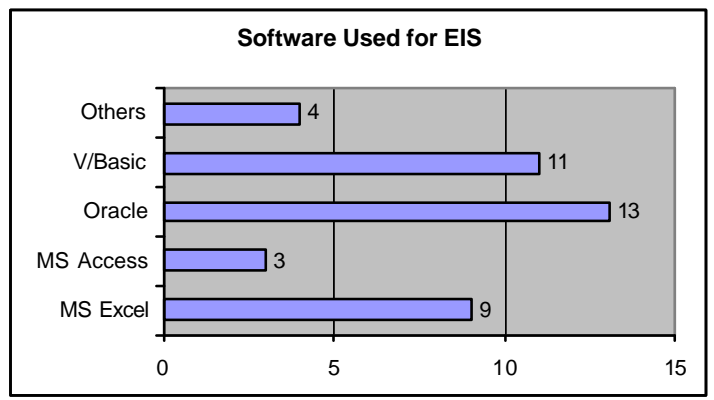

In $33 \%$ of the institutions, Oracle is applicable as database tool and in $27 \%$ of the institutions, Visual Basic is applicable. In some of the institutions database is only limited to maintaining sheet on the MS Excel i.e., 23\%. In $50 \%$ of the institutions the Windows NT is used as operating system wheras Windows 2000 Server is also becoming very popular as operating system which is $27 \%$.

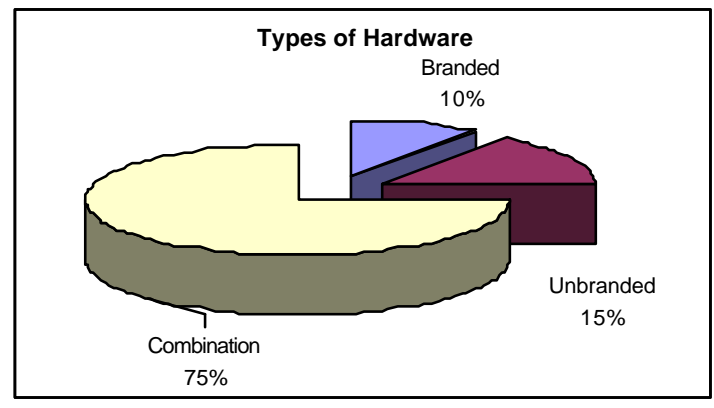

In most of the institutions, hardware is the combination of branded and unbranded systems i.e., 75\% institutions have both the types of hardware. As far as application of MS Office software is concerned, it is applicable to $96 \%$ of the

institutions without the discrimination that whether they have EIS. Most of the institutions where computerization have not been made are giving reasons such as shortage of funds, lack of infrastructure support and least concerned of top management for implementing information system.

\section{CONCLUSIONS \& RECOMMENDATIONS}

It has been concluded from the survey that only $15 \%$ institutions have all core educational information systems applicable which is not very appreciating. The situation in private institutions is far better than that of government owned institutions where due to non-availability of information systems, results and registrations are delayed, students' records are maintained improperly and sorted manually. Due to non- computerization, overall operational efficiency of academic administrative matters badly effects. Institutions have taken initiative and now moving towards implementing educational information systems in order to facilitate academic administrative matters. It has been found that computerization of academic administration is likely to be implemented if top management of the institutions take interest. Further, there is need of software houses, which may be specialized in developing educational information systems. There are hundreds of software houses but their concentration is more towards providing information systems solutions to business organizations. Most of the government educational institutions in particular and private in general are not-for-profit organizations where government has to take initiative to computerize the academic operations by providing free information system and hardware. It should be made mandatory for all institutions to have their websites, e-mail addresses and computer generated results and this to be monitored thoroughly. No institution has denied the importance of application of educational information system but lack of initiative, top management's interest, financial support and infrastructure are the major hurdles towards computerization in the educational institutions. In concluding, it shows that the inclination towards computerization is increasing and institutions without educational information systems will have no choice except to implement information system in order to bring overall efficiency in academic administrative matters that will have direct impact on the core academic matters of the institutions.

\section{REFERENCES}

[1] Muhammad Kamran Jamil (MKJ):Syed Asad Hussain (SAH); 2003; Application of Information System in the Education industry of Pakistan; SZABIST; Page 1

[2] Steven Alter; 1998; Information Systems - A Management Perspective; The Benjamin/Cummings Publishing Company, Inc.; Singapore; Pages 14-30, 242-272, Total Pages 728

[3] Muhammad Kamran Jamil (MKJ):Syed Asad Hussain (SAH); 2003; Application of Information 
System in the Education industry of Pakistan; SZABIST; Page 6 \& 7

[4] Parvaiz Naim Dr.; October 6, 2002; Time to Stand Up for Change; The Dawn Dawn; Karachi; Page 25

[5] Muhammad Kamran Jamil (MKJ):Syed Asad Hussain (SAH); 2003; Application of Information System in the Education industry of Pakistan; SZABIST; Page 5

[6] Khalid Mahmood; 1998; Information Technology in Libraries - "A Pakistani Perspective"; Pak
Book Corporation; Lahore; Pages 9-16; Total Pages 256

[7] Muhammad Kamran Jamil (MKJ):Syed Asad Hussain (SAH); 2003; Application of Information System in the Education industry of Pakistan; SZABIST; Page 6

[8] Muhammad Kamran Jamil (MKJ):Syed Asad Hussain (SAH); 2003; Application of Information System in the Education industry of Pakistan; SZABIST; Page 8. 